\title{
Older doctors and retirement
}

\author{
Brian M Draper
}

\section{Planning for life after work should commence as early as possible}

$\mathrm{M}$ any older doctors work beyond the traditional retirement age of 65 and have no clear retirement plans, as discussed by Wijeratne and colleagues in this issue of the $M J A .{ }^{1}$ Yet it is also known that older doctors are at higher risk of poor performance. ${ }^{2}$ The move towards revalidation, as being considered by the Medical Board of Australia (MBA), should be regarded as complementary to retirement planning, in that both involve components that need to start early in the doctor's career. Successful retirement usually requires the doctor to have interests outside medicine, financial security, and good health, each of which should be developed during a long career. The trend to later retirement was noted 15 years ago. ${ }^{3}$ Since then, there has been a further ageing of the medical workforce, and around 1700 employed doctors in Australia are 75 or older, particularly in general practice, psychiatry, ophthalmology and general medicine. ${ }^{4}$ This delay in retirement is consistent with baby boomer trends in the general population.

A recent systematic review of retirement planning by doctors found that continuing financial obligations delayed retirement, while strategies to mitigate career dissatisfaction, workplace frustration, and workload pressure supported their continuing to practice. ${ }^{6}$ Many of these factors are mirrored in the published literature about retirement in general. ${ }^{5,7}$ For some doctors, the centrality of work and a sense of responsibility for their patients, particularly if a replacement cannot be found to continue the practice, may add another dimension to retirement planning. ${ }^{1,8}$

Older doctors are acknowledged to have important mentorship, educational, leadership, medico-legal, and other roles in medicine. These benefits are counterbalanced by evidence that they have less factual knowledge, are less likely to adhere to standards of care, and may also achieve poorer patient outcomes. ${ }^{2}$ Such factors are among the drivers for the move towards revalidation of the medical workforce in Australia. According to the interim report of the MBA Expert Advisory Group on revalidation, the risk of poor performance increases with age. ${ }^{9}$ Both revalidation, defined as "the process by which doctors have to regularly show that they are up to date, and fit to practice medicine ${ }^{\prime \prime}{ }_{1}^{10}$ and retirement planning could be conceptualised as linked whole-of-career features, as noted by findings that retirement in the general population is influenced by life course, health, finances and work-life balance. ${ }^{6}$

A key problem, highlighted by Wijeratne and his co-authors, ${ }^{1}$ is the extent to which the medical career is central to the doctor's life compared with their other life roles, including their marital and other intimate relationships. Relationships need to be nurtured throughout the career, and are particularly affected by overwork and using work to avoid dealing with communication and intimacy difficulties. ${ }^{11}$ Relationship and family problems are commonly cited reasons for retiring. ${ }^{1,8}$ Important lifestyle decisions can also be made early in the career that may accrue increasing value over time, eventually facilitating the retirement process and promoting

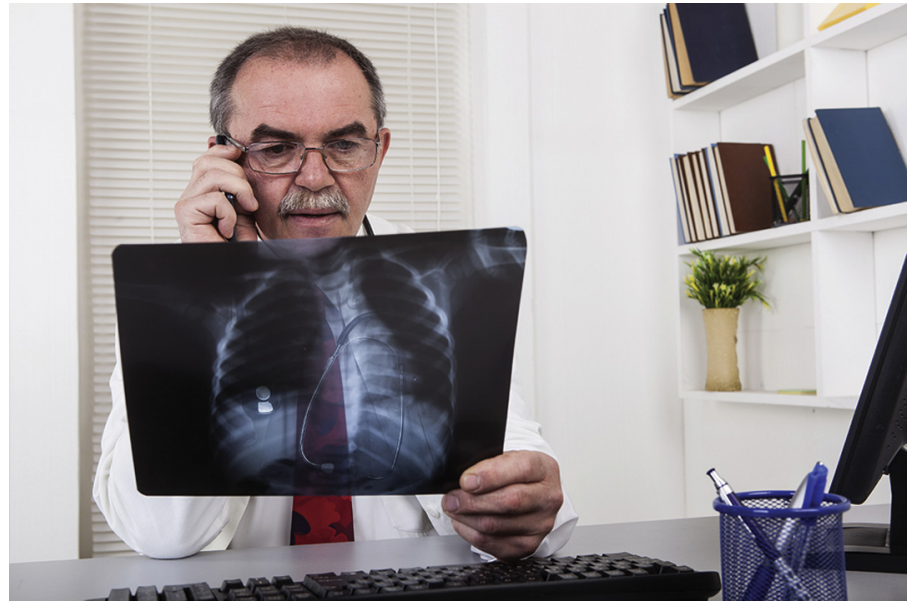

satisfaction after retirement. Balancing work commitments with relationships and interests, such as the arts, sport, hobbies, and travel, is important throughout one's career.

Financial security is a second factor that influences retirement decisions, and many doctors extend their careers for this reason. ${ }^{1,3,6}$ While doctors working in the public sector are likely to have superannuation schemes with employer contributions, those who are self-employed, particularly general practitioners, can find it challenging to maintain a financial situation that provides an adequate, sustainable retirement income. ${ }^{2}$ Doctors need to obtain financial advice and develop a financial plan from early in their career, particularly if they are self-employed.

A third pillar of whole-of-career planning is the doctor's own health. There is good evidence that health in later life is enhanced by attention to midlife lifestyle, including diet, exercise, health monitoring, and moderation of the use of alcohol and other drugs. ${ }^{12}$ A doctor having a GP is an important component of health monitoring, and may help avert self-neglect. ${ }^{11}$ Deteriorating health influences the decision to retire, ${ }^{8}$ but when finances are uncertain or the doctor has a dearth of other interests, such decisions may be compromised. It is noteworthy that the Royal Australasian College of Surgeons (RACS) changed its continuing professional development $(\mathrm{CPD})$ regulations to include requiring ageing surgeons to have their own GP and to undergo regular health checks. ${ }^{13}$

The RACS includes modified performance requirements for ageing surgeons in their CPD program. This is consistent with the proposed model for revalidation of medical practitioners in Australia, which includes enhanced CPD and proactively identifying doctors who are either performing poorly or are at risk of poor performance. ${ }^{9,13}$ This style of CPD program also has the potential to assist older doctors to gradually step down from practice by progressively reducing work hours, modifying their responsibilities, developing new interests, and eventually retiring altogether. GPs and psychiatrists, given their ageing workforce and being less likely to intend to retire, might particularly benefit from such an approach. ${ }^{1,4}$ How to better identify the cognitively impaired doctor and assist their retirement has yet to be adequately addressed by 
the medical profession, but the increasing number of practising doctors over the age of 75 means that it needs to be discussed. ${ }^{4}$

The medical workforce will continue to age with the passing of the baby boomer generation, and older doctors will retain an integral productive role in health care, as do older workers in the general population. ${ }^{14}$ Although it might be easier for older doctors to retire if they have considered financial, health, lifestyle and professional issues earlier in their career, late career attention to these factors can still be beneficial. Healthy ageing programs have long established that even late adoption of lifestyle changes can have improve the wellbeing of older people. ${ }^{15}$ The ageing medical workforce may present the profession with challenges, but, as in the broader community, these challenges are not insurmountable.

Competing interests: No relevant disclosures.

Provenance: Commissioned; externally peer reviewed.

(c) 2017 AMPCo Pty Ltd. Produced with Elsevier B.V. All rights reserved.

1 Wijeratne C, Earl JK, Peisah C. Professional and psychosocial factors affecting the intention to retire of Australian medical practitioners. Med J Aust 2017; 206: 209-214.

2 Choudhry NK, Fletcher RH, Soumerai SB. Systematic review: the relationship between clinical experience and the quality of health care. Ann Intern Med 2005; 142: $260-273$

3 Schofield DJ, Beard JR. Baby boomer doctors and nurses: demographic change and transitions to retirement. Med J Aust 2005; 183: 80-83. https://www.mia.com.au/ journal/2005/183/2/baby-boomer-doctors-and-nurses-demographic-change-andtransitions-retirement
4 Australian Institute of Health and Welfare. National health workforce dataset: medical practitioners 2015. http://www.aihw.gov.au/workforce/medical/ (accessed Nov 2016).

5 Bidewell J, Griffin B, Hesketh B. Timing of retirement: including a delay discounting perspective in retirement models. J Voc Behav 2006; 68: 368-387.

6 Silver MP, Hamilton AD, Biswas A, Warrick NI. A systematic review of physician retirement planning. Hum Res Health 2016; 14: 67.

7 Davey. What influences retirement decisions? Soc Pol J New Zealand 2008; 33: 110-125.

8 Draper B, Winfield S, Luscombe G. The older psychiatrist and retirement. Int J Geriatr Psychiatry 1997; 12: 233-239.

9 Medical Board of Australia, Expert Advisory Group on revalidation. Options for revalidation in Australia: interim report. Aug 2016. http://www.medicalboard.gov.au/ documents/default.aspx?record=WD16\%2f21165\&dbid=AP\&chksum=eyQKBp1 FQqEkNOnzlVenUg\%3d\%3d (accessed Nov 2016).

10 Bolsin SN, Cawson E, Colson ME. Revalidation is not to be feared and can be achieved by continuous objective assessment. Med J Aust 2015; 203: 142-144. https://www.mja.com. au/journal/2015/203/3/revalidation-not-be-feared-and-can-be-achieved-continuousobjective-assessment

11 Myers MF. Medical marriages and other intimate relationships. Med J Aust 2004; 181: 392-394. https://www.mja.com.au/journal/2004/181/7/medical-marriages-and-otherintimate-relationships

12 Lafortune L, Martin S, Kelly S, et al. Behavioural risk factors in mid-life associated with successful ageing, disability, dementia and frailty in later life: a rapid systematic review. PLOS One 2016; 11: e0144405.

13 Waxman BP. The aging psychiatrist: lessons from our colleagues in surgery and anaesthesia. Aust Psychiatry 2016; 24: 155-156.

14 Burtless $\mathrm{G}$. The impact of population aging and delayed retirement on workforce productivity [working paper, WP\#2013-11]. Center for Retirement Research at Boston College, 2013. http://crr.bc.edu/working-papers/the-impact-of-population-agingand-delayed-retirement-on-workforce-productivity/ (accessed Jan 2017).

15 National Ageing Research Institute. Healthy ageing literature review. Final report to the Department of Health and Human Services. Melbourne: DHHS, 2016. https://www2 health.vic.gov.au/about/publications/policiesandguidelines/healthy-ageing-literaturereview (accessed Nov 2016). 